\section{Lecture Experiments on Colour}

For some time $I$ have been taking an active interest in the phenomena of colour, and have read with much pleasure the papers of Mr. Strutt and other gentlemen, and the abstract of the interesting lecture recently delivered at the Royal Institution by Prof. Maxwell. I have repeated many of the experiments of these observers, and have successfully exhibited them in public in a modified form, and in a way which can be readily repeated by other lecturers without the aid of the elaborate contrivance use t by Prof. Maxwell. The following experiments make no pretension to rigid accuracy, but are merely described as striking lecture-table demonstrations of well-ascertained but little known scientific facts. I use the lime light for their exhibition, as it suits my convenience better than the electric light, though many lecturers prefer the latter.

A beam of light from the lantern is passed through a slit, focussed by a lens, refiacted by a disulphide of carbon prism, and the spectrum exhibited in the usual way. A flat cell containing a solution of potassium permanganite is next placed in front of the slit. With a weak solution and narrow slit a series of black bands are produced in the green part of the spectrum, but with a stronger solution the green and yellow are completely cut out, allowing only the red and deep blue lights to pass. On widening the slit these bands of coloured light of course increass in width also, gradually approaching each other until they overlap, producing a fine purple by their admixture.

If the experiment be repeated, substituting for the permanganste an alkaline mixture of litmus and potassium chromate in certain proportions, only the red and green light are transmited, the blue, and especially the yellow, being completely ab sorbet. On widening the slit as before, the red and green bands overlap, and produce by their union a very fine compound yellow, while the constituent red and green are still visible on each side. The effect is most striking when by the widening of the slit round hole is exposed in its place, when there appear on the screen two circles, respectively green and red, producing bright yellow by their admixture. This experiment is the more strikin. yello by the process of absorbing the simple yellow. The mixture above described (suggested by Mr. Strutt) answers better than a solution of chromic chloride.

Of course, it is a well-known fact that all natural yellows give a spectrum of red, yellow, and green, and a common effect illustrating the compound nature of yellow is noticed when exhibiting a continuous spectrum on a screen. When the slit is narrow the green is very fully developed, and only separated from the red by a very narrow strip of yellow, while on gradually increasing the width of the slit the red and green are seen to overlap, producing the brilliant yellow we generally notice. Thit; the purer the spectrum the less yellow is observed.

If the continuous spectrum be produced with a quariz prism, a little management and adjustment of the distance of the screen will cause the two spectra to overlap, so that the red of one may be made to coincide with the green, blue, or any desired tint of the other. The same result is obtained by employing two slits at the same time, the distance between which can be adjusted. By this means two spectra are obtained simultaneously, any portions of which can be made to coincide.

I have not tried to use a double refracting Nicol's prism, as is suggested by Mr. Strutt in the number of NATURE for June 22.

A saturated solution of potassium chromate absorbs all rays more refrangible than the green, while a solution of ammoniosulphate of copper stops all but the blue and green. These statements may be proved by placing flat cells containing the liquids in front of the slit of the lantern, and on placing one cell in front of the other in the same position the green light only is transmitted. This experiment serves to explain the reason that the mixture of yellow and blue generally results in green, all other rays being absorbed by one or other of the constituents.

By placing the two cells in front of separate lanterns, and throwing discs of light on the screen, a beautifully pure white is produced where the blue and yellow overlap.

I employ one lantern only for this experiment, using two focussing lenses side by side to produce the overlapping circles of light.

I also employ a cell with three compartments, containing solutions of aniline red, ammonio-sulphate of copper, and a mixture of potassium chromate with the last solution, and projecting images on the screen by means of three lenses fitted on the same stand but capable of separate adjustment. I can thus exhibit overlapping circles of brilliant red, blue, and green light, which produce a perfect white by their admixture, while at the same time there is seen the compound yellow produced by the union of $\mathbf{r} \approx d$ and green, the purple arising from the red and blue, and a colour varying from grass green to sky blue produced by the combination of the green and blue light. This experiment has the advantage of exhbiting at the same time the three primary colours-red, gretn, and blue-the compound colours produced by theirmixture, their complementary tints, and the synthesis of white light

The flat cells mentioned are made by cutting thin pieces of board to the desiced shape, and cementing pieces of window glass on each side by means of pitch.

Sheffield, June 26

ALFRED H. ALIEN

\section{Mr. Stone and Prof. Newcomb}

I AM sorry, indeed, that anything in my answer to Prof. Newcomb should be unsatisfactory to Mr. Stone. It will certainly be hard if after drawing upon myself Prof. Newcomb's indigna. tion by advocating Mr. Stone's claims, I should find that I have unwittingly offended Mr. Stone also.

It is the misfortune of a writer on science that he has often to deal with overlapping claims; and when he adheres unflinchingly (as I have always done) to what he regards as the strict line of truth, he cuts off a little from the claim; on either side, and so offends both claimants. I have found myself in the same difficuity as respects the work of Dr. De la Rue and Fr. Secc hi, in 1860 , and I fear the result may have been the same in that case also.

In another case, that of Mr. Lockyer and his fellow-ivorkers in spectroscopic solar researches, I freely admit that what I regarded as the line of truth when $I$ wrote "The Sin," I now no longer regard as strictly such, evidence having been produced which has satisfied me to that effect. Even in this case, however, I have in the first place very little to correct, and in the second I am by no means certain that I shall be able to satisfy all or any of those corcerned.

Fortunately or mafortunately, the writer who cannot please all proves equally his desire to do justice to all by leaving all dissatisfied. This is commonly the fate of the true neutral. I must confess, however, that I cannot see what reason Mr. Stone has for being dissatisfied, since I have ascribed to him, much to Prof. Newcomb's dissatisfaction, the final and complete solution of a problem which both have dealt with very ably. I am still waiting to hear the nature of Prof. Newcomb's objections. Whatever they may be, I am assured of this-that in defending (if I can defend) my owa work, I shall be advocating Mr. Stone's claims. I hope that in so doing I shall not very grievously offend that gentleman, towards whom I eatertain the most friendly feelings, Richari). A. PROCTOR

\section{Saturn's Rings}

The reviewer of Lieut. Davies's work on Meieors has somewhat misunderstood the extent to which $I$ have been indebted (in preparing my treatise on Saturn) to Prof. Maxwell's excellent "Essay on the Saturnian Ring-System." I have quoted in all two and a half lines from that essay, with proper reference to it, and I have devoted one-third of a page to summarising the most important section of the essay. All the rest of my chapter on the Nature of the Rings was written before I had seen Prof. Maxwell's contribution to the meteoric theory of the ring-system. I may add that every result in Saturn, which is not distinctly referred to authority, or else obviously common property, has been worked out by myself, as my note-books will abundantly testify.

Brighton, August 28

RICHARD A, PROCTOR

\section{A Rare Phenomenon}

SUNDAY, the I $3^{\text {th }}$ August, and several days before, having been very hot and dry, a great deal of dust was suspended in the atmo sphere, which caused without doubt the intense red colour of the setting sun, and might contribute to the phenomenon $I$ am about to describe. This plenomenon may easily be understood by $m$ eans of a globe bisected by a meridian plane, one half of it representing the celestial vault. Beginning at the eastern end of the equator, the space between the 40th and 50th degree of longitude may be tinged with redaish grey; then the space between the 6oth and $75^{\text {th }}$ degree, further, that between the 